\title{
Early-age compressive strength and dynamic modulus of FRC based on ultrasonic pulse velocity
}

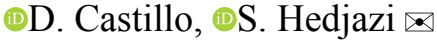 \\ Civil Engineering and Construction Department, Georgia Southern University, (Georgia, USA) \\ $\checkmark$ shedjazi@georgiasouthern.edu
}

Received 01 December 2020

Accepted 18 May 2021

Available on line 30 July 2021

\begin{abstract}
Due to the increasing use of rapid construction methods and the challenges of maintaining construction schedules, a growing demand exists for procedures that can assure quality of work without sacrificing the pace of construction. The quality control of construction materials specifically, the mechanical properties of concrete are among the most important concerns in today's construction industry. In the present study, the correlation between fiber-reinforced concrete's compressive strength and dynamic modulus to its ultrasonic pulse velocity is investigated at early ages up to 7 days after mixing. An experimental program involving 189 FRC specimens were designed containing different types of structural fibers, fiber volume fractions, and water-tocement ratios. Mathematical equations were developed to predict the early-age compressive strength and dynamic modulus of four different types of fiber-reinforced concrete based on ultrasonic pulse velocity. The predicted compressive strength and dynamic modulus from the proposed equations showed good agreement with the measured ones.
\end{abstract}

KEY WORDS: Fibre reinforcement; Mechanical properties; Compressive strength; Modulus of elasticity; Concrete.

Citation/Citar como: Castillo, D.; Hedjazi, S. (2021) Early-age compressive strength and dynamic modulus of FRC based on ultrasonic pulse velocity. Mater. Construcc. 71 [343], e257. https://doi.org/10.3989/mc.2021.14720.

RESUMEN: Determinación de la resistencia a compresión temprana y el módulo de elasticidad de HRF mediante la velocidad de paso del pulso ultrasónico. Debido al aumento del empleo de métodos rápidos de construcción y los desafíos de mantener los calendarios de construcción, ha aumentado la demanda de procedimientos que permitan asegurar la calidad del trabajo sin sacrificar el ritmo de producción. Dentro del control de calidad de los materiales de construcción, las propiedades mecánicas del hormigón se encuentran entre las preocupaciones más importantes. En este estudio se investiga la correlación entre la resistencia a la compresión y el módulo dinámico del hormigón reforzado con fibras, con la velocidad de pulso ultrasónico a edades tempranas hasta 7 días después del amasado. Para ello se diseñó un programa experimental que involucró 189 muestras de HRF que contenían diferentes tipos de fibras estructurales, fracciones de volumen de fibra y relaciones agua/cemento. Se desarrollaron ecuaciones matemáticas para predecir la resistencia a la compresión y el módulo dinámico a edades tempranas de cuatro tipos diferentes de hormigón reforzado con fibras, en función de la velocidad del pulso ultrasónico. Tanto la resistencia a la compresión como el módulo dinámico pronosticados a partir de las ecuaciones propuestas mostraron una buena correlación con las medidas experimentales llevadas a cabo.

PALABRAS CLAVE: Refuerzo de fibras; Propiedades mecánicas; Resistencia a la compresión; Módulo de elasticidad; Hormigón.

Copyright: (C2021 CSIC. This is an open-access article distributed under the terms of the Creative Commons Attribution 4.0 International (CC BY 4.0) License. 


\section{INTRODUCTION}

To ensure the safety, long-term performance, and durability of concrete structures in an accelerated construction schedule, an understanding of concrete behavior and an evaluation of its mechanical properties at early ages plays an important role in the construction quality control and planning process. Concrete's compressive strength and dynamic modulus at an early age dramatically impact its long-term efficiency, durability, and properties. Early age of concrete is typically defined as the first few hours or days after casting concrete, which is marked by the setting and hardening processes as hydration occurs. During this time, the fluid phase of fresh concrete transitions into the hardened state, resulting in the development of mechanical properties, heat release, and deformations due to the success of the hydration reactions. The mechanical properties of early-age concrete develop at different rates, depending on mixture proportions, including the fiber content, water-to-cement $(\mathrm{w} / \mathrm{c})$ ratio, age, and curing conditions $(1,2)$. For example, while the gain in concrete compressive strength is rapid at an early age, with approximately $65-75$ percent of the compressive strength reached in the first 7 days, the gain in concrete elastic modulus is extremely rapid at an early age, with approximately 90 percent of the elastic modulus reached in the first 24 hours. This rapid, early gain in strength and dynamic modulus is directly linked to the increase of the gel/space ratio of calcium silicate hydrate, and it can be affected by the change in mix proportions, such as the addition of fiber reinforcement (3).

Concrete is a widely used construction material due to its high compressive strength, although it has a relatively low tensile strength when compared to other construction materials. Therefore, concrete is often reinforced with structural fibers to enhance its mechanical and physical properties. Fiber-reinforced concrete (FRC) is classified into steel fiber-reinforced concrete (SFRC), glass fiber-reinforced concrete (GFRC), synthetic fiber-reinforced concrete, and natural fiber-reinforced concrete (4). Traditionally, to ensure the quality, durability, and safety of concrete, the compressive strength of cylindrical concrete specimens is determined experimentally using a destructive test (5), and the static modulus of elasticity of concrete is calculated using a similar destructive test (6). However, these destructive test methods are outdated for three reasons. First, they are time-consuming because strength requirements are typically calculated after 28 days when most of the concrete strength is achieved. Second, they require several samples since the test method is destructive and compliance with the standards demands at least the average of a few samples measured at the same age. Third, the workload is high and expensive for sampling, curing, and trans- porting, and for the testing equipment. In addition, the use of these test methods for in-service evaluation is inefficient because cores need to be extracted from the structure, and extracting too many cores will harm the integrity of the structure and the data obtained are confined to the cores' locations.

As an alternative to destructive testing, several studies exist in the literature containing empirical equations based on nondestructive test methods, such as the ultrasonic pulse velocity (UPV), to predict the compressive strength and dynamic modulus of concrete (7-9). Most of these studies focus on predicting plain concrete's compressive strength and dynamic modulus based on UPV after 28 days, while considering mixture parameters such as cement type, cement content, aggregate size, aggregate content, and $\mathrm{w} / \mathrm{c}$ ratio. Studies including the effects of a wider mixture of parameters, such as the addition of different types of fibers and different fiber volume fractions on UPV, are limited and cannot be utilized for all types of FRC and at different ages. On the other hand, it has been proven that the fibers influence the compressive strength, the duration for the peak load, and the energy absorption under uniaxial compressive loading at the early ages (10). Subsequently, there is a need for equations specifically proposed to predict the early-age compressive strength and dynamic modulus of different types of FRC based on UPV.

A number of research studies have investigated the relationship between UPV and the compressive strength and dynamic elastic modulus of plain concrete. However, as discussed, better estimation of these properties in terms of the ultrasonic pulse velocity measurement depends on numerous mixture parameters, such as fiber type and volume fraction, $\mathrm{w} / \mathrm{c}$ ratio, temperature, coarse aggregate, shape, and cement type $(7,8,11)$. While plain concrete was the focus of many studies (7-9, 12-14), the addition of structural fibers was either ignored or limited to a specific type of fiber. Additionally, the relationship between the steel fiber-reinforced concrete's UPV and its compressive strength was studied extensively, but fewer studies can be found for polypropylene, nylon, and glass fiber-reinforced concrete (15-18). One investigation of the relationship between the compressive stress and the strain of steel fiber-reinforced concrete at early age showed that the fiber content and age of concrete affect the energy absorption of FRC (10). Therefore, the effect of different types of structural fibers on the early-age compressive strength and the modulus of elasticity of FRC at various fiber volume fractions needs to be investigated further.

In the present study, FRC cylindrical specimens were cast, cured, and tested for compressive strength, dynamic modulus, and ultrasonic pulse velocity. The cement type and aggregate size remained constant, while the effect of change in fiber type, fi- 
ber volume fraction, water-to-cement ratio, and test age on the prediction of FRC compressive strength and dynamic modulus were investigated. Two sets of new empirical equations were proposed to predict the compressive strength and dynamic modulus of FRC based on UPV. The first set of equations predicted the compressive strength of early-age steel, polypropylene, nylon, and glass FRC. The second set of equations predicted the dynamic modulus of early-age steel, polypropylene, nylon, and glass FRC. The accuracy of these new equations was tested by measuring the coefficient of variation between the measured values and the predicted values from the proposed equations.

TABLE 1. Experimental program outline.

\begin{tabular}{|c|c|}
\hline Portland Cement & Type I/II \\
\hline $\begin{array}{l}\text { Coarse Aggregate Maximum } \\
\text { Size }\end{array}$ & $4.7625 \mathrm{~mm}\left(0.1875^{\prime \prime}\right)$ \\
\hline Fiber Types & $\begin{array}{l}\text { Nylon, polypropylene, steel, } \\
\text { and glass }\end{array}$ \\
\hline Fiber Volume Fraction (\%) & $0.5,1.0$, and 1.5 \\
\hline Water-to-Cement Ratio & $0.40,0.45$, and 0.50 \\
\hline Specimen Geometry & $\begin{array}{l}\text { Cylinder } 100 \mathrm{~mm} \times 200 \mathrm{~mm} \\
\left(4^{\prime \prime} \times 8^{\prime \prime}\right)\end{array}$ \\
\hline Curing Time (days) & $1,3,7,28$ \\
\hline Destructive Test & Compression test machine \\
\hline Nondestructive Tests & $\begin{array}{l}\text { Ultrasonic concrete tester, } \\
\text { resonance test gauge }\end{array}$ \\
\hline $\begin{array}{l}\text { Mechanical Properties } \\
\text { Evaluated }\end{array}$ & $\begin{array}{l}\text { Compressive strength, } \\
\text { dynamic modulus }\end{array}$ \\
\hline
\end{tabular}

\section{EXPERIMENTAL PROGRAM}

An experimental program was designed and conducted to establish a correlation between FRC's early-age UPV and its early-age compressive strength and dynamic modulus. This program involved 189 specimens of $100 \mathrm{~mm} \times 200 \mathrm{~mm}$ FRC cylinders with different mixture proportions. The UPV, dynamic modulus, and compressive strength were measured using an ultrasonic concrete tester, a resonance test gauge, and a compression test machine, respectively. The experimental program outline is shown in Table 1.

\subsection{Materials}

Portland cement type I/II was combined with gravel; sand; water; and nylon, polypropylene, steel, and glass fibers to produce four different types of FRC. The fiber properties are presented in Table 2.

\subsection{Mixture proportions}

Reinforcing fibers are added to concrete at different dosages depending on the intended application and fiber type. Table 3 shows the fiber addition rates that manufacturers recommend, and Table 4 lists studies that examined the performance of various types of fiber-reinforced concrete at different fiber volume fractions. It can be observed from Table 3 and Table 4 that the fiber volume fraction range of $0 \%$ vol. to $1.0 \%$ vol. is applicable for all types of fibers considered in this investigation. In addition, having the same fiber volume fraction range allows

TABLE 2. Fiber properties (19).

\begin{tabular}{lcccc}
\hline & Stainless Steel & AR Glass & Virgin Nylon & Polypropylene \\
\hline Filament Diameter, d $(\mathbf{m m})$ & 1.18 & 0.014 & 0.038 & 1.52 \\
\hline Fiber Length, $\mathbf{I}(\mathbf{m m})$ & 25.4 & 13 & 19 & 19 \\
\hline Density, $\boldsymbol{\rho}\left(\mathbf{k g} / \mathbf{m}^{\mathbf{3}}\right)$ & 7800 & 2700 & 1150 & 910 \\
\hline Tensile Strength, $\boldsymbol{\tau}(\mathbf{M P a})$ & 1030 & 2000 & 300 & 410 \\
\hline Flexural Strength, $\boldsymbol{\sigma}(\mathbf{G P a})$ & 203 & 77 & 2.8 & 5.6 \\
\hline Melting Point $\left(\mathbf{~}^{\circ} \mathbf{C}\right)$ & 1516 & 1121 & 225 & 160 \\
\hline Water Absorption & Nil & $<1 \%$ & $3 \%$ by Weight & Nil \\
\hline Alkali Resistance & High & High & High & Excellent \\
\hline Corrosion Resistance & High & High & High & High \\
\hline
\end{tabular}

TABLE 3. Manufacturer-recommended fiber addition rates (19).

\begin{tabular}{ccccc}
\hline Fiber Addition Rates & Nylon & Polypropylene & Steel & Glass \\
\hline Plastic Shrinkage Cracking & $0.6 \mathrm{~kg} / \mathrm{m}^{3}$ & $0.9 \mathrm{~kg} / \mathrm{m}^{3}$ & $10-15 \mathrm{~kg} / \mathrm{m}^{3}$ & $0.3-0.6 \mathrm{~kg} / \mathrm{m}^{3}$ \\
\hline Structural Performance & - & - & $15-80 \mathrm{~kg} / \mathrm{m}^{3}$ & $5-15 \mathrm{~kg} / \mathrm{m}^{3}$ \\
\hline
\end{tabular}


for easy comparison between fibers. Therefore, the research team designed 21 mixes comprising nylon, polypropylene, steel, and glass fibers at fiber volume fractions (Vf) of $0.5 \%$ vol., $0.75 \%$ vol., and $1.0 \%$ vol., and w/c ratios of $0.40,0.45$, and 0.50 . Table 5 shows the different concrete mix proportions; $\mathrm{Vf}$ is fiber volume fraction, $\mathrm{W} / \mathrm{C}$ is water-to-cement ratio, $\mathrm{C}$ is cement, $\mathrm{CA}$ is coarse aggregate, $\mathrm{FA}$ is fine aggregate, and $\mathrm{W}$ is water.

TABLE 4. Common fiber volume fraction ranges.

\begin{tabular}{cccccc}
\hline & & \multicolumn{5}{c}{ Fiber Volume Fraction (Vf) Ranges } \\
\cline { 3 - 6 } No. & Reference & Steel & Glass & Nylon & $\begin{array}{c}\text { Polypro- } \\
\text { pylene }\end{array}$ \\
\hline 1 & $(15)$ & $0-2 \%$ & - & - & - \\
\hline 2 & $(20)$ & - & $0-5 \%$ & - & - \\
\hline 3 & $(21)$ & $0-2 \%$ & - & - & - \\
\hline 4 & $(22)$ & - & $0-2.4 \%$ & - & - \\
\hline 5 & $(16)$ & - & - & $0-1.5 \%$ & - \\
\hline 6 & $(23)$ & $0-1.5 \%$ & - & - & - \\
\hline 7 & $(24)$ & - & - & - & $0-2 \%$ \\
\hline 8 & $(18)$ & $0-2 \%$ & - & - & $0-2 \%$ \\
\hline
\end{tabular}

\subsection{Specimen preparation}

Twenty-one separate mixes (batches) were prepared and nine specimens per mix were produced, yielding a total of 189 specimens. These $189 \mathrm{spec}-$ imens were categorized into five groups: the first group (Mix 1) had specimens with no fibers, the second group (Mixes 2-6) had specimens with nylon fibers, the third group (Mixes 7-11) had specimens with polypropylene fibers, the fourth group (Mixes 12-16) had specimens with steel fibers, and the fifth group (Mixes 17-21) had specimens with glass fibers. The concrete was mixed, placed, consolidated, and cured in accordance to ASTM C192 (25).

\subsection{Ultrasonic pulse velocity measurement}

The ultrasonic pulse velocity of each specimen was determined according to ASTM C597 (26) after the specimens had cured in water for $1,3,7$, and 28 days. The UPV was determined by the direct transmission configuration, where the transmitter and receiver transducers are placed directly opposite each other on parallel surfaces. The pulse velocity (V) was calculated by dividing the length (L) of the

TABLE 5. Mixture proportions.

\begin{tabular}{|c|c|c|c|c|c|c|c|c|}
\hline Fiber Type & ID & $V f(\%)$ & $\mathbf{W} / \mathbf{C}$ & $\mathrm{C}\left(\mathrm{kg} / \mathrm{m}^{3}\right)$ & $\mathrm{CA}\left(\mathrm{kg} / \mathrm{m}^{3}\right)$ & FA $\left(\mathbf{k g} / \mathbf{m}^{3}\right)$ & $\mathrm{W}\left(\mathrm{kg} / \mathrm{m}^{3}\right)$ & Fiber $\left(\mathrm{kg} / \mathrm{m}^{3}\right)$ \\
\hline Plain Concrete & Mix 1 & 0.00 & 0.40 & 503.3 & 709.7 & 986.5 & 201.3 & 0.0 \\
\hline \multirow{5}{*}{ Nylon } & Mix 2 & 0.50 & 0.40 & 500.8 & 706.1 & 981.5 & 200.3 & 5.7 \\
\hline & Mix 3 & 0.75 & 0.40 & 499.5 & 704.3 & 979.1 & 199.8 & 8.5 \\
\hline & Mix 4 & 1.00 & 0.40 & 498.3 & 702.6 & 976.6 & 199.3 & 11.4 \\
\hline & Mix 5 & 0.75 & 0.45 & 487.3 & 687.1 & 955.0 & 219.3 & 8.5 \\
\hline & Mix 6 & 0.75 & 0.50 & 475.6 & 670.6 & 932.1 & 237.8 & 8.5 \\
\hline \multirow{5}{*}{ Polypropylene } & Mix 7 & 0.50 & 0.40 & 500.8 & 706.1 & 981.5 & 200.3 & 4.5 \\
\hline & Mix 8 & 0.75 & 0.40 & 499.5 & 704.3 & 979.1 & 199.8 & 6.8 \\
\hline & Mix 9 & 1.00 & 0.40 & 498.3 & 702.6 & 976.6 & 199.3 & 9.1 \\
\hline & Mix 10 & 0.75 & 0.45 & 487.3 & 687.1 & 955.0 & 219.3 & 6.8 \\
\hline & Mix 11 & 0.75 & 0.50 & 475.6 & 670.6 & 932.1 & 237.8 & 6.8 \\
\hline \multirow{5}{*}{ Steel } & Mix 12 & 0.50 & 0.40 & 500.8 & 706.1 & 981.5 & 200.3 & 39.0 \\
\hline & Mix 13 & 0.75 & 0.40 & 499.5 & 704.3 & 979.1 & 199.8 & 58.5 \\
\hline & Mix 14 & 1.00 & 0.40 & 498.3 & 702.6 & 976.6 & 199.3 & 78.0 \\
\hline & Mix 15 & 0.75 & 0.45 & 487.3 & 687.1 & 955.0 & 219.3 & 58.5 \\
\hline & Mix 16 & 0.75 & 0.50 & 475.6 & 670.6 & 932.1 & 237.8 & 58.5 \\
\hline \multirow{5}{*}{ Glass } & Mix 17 & 0.50 & 0.40 & 500.8 & 706.1 & 981.5 & 200.3 & 13.5 \\
\hline & Mix 18 & 0.75 & 0.40 & 499.5 & 704.3 & 979.1 & 199.8 & 20.2 \\
\hline & Mix 19 & 1.00 & 0.40 & 498.3 & 702.6 & 976.6 & 199.3 & 27.0 \\
\hline & Mix 20 & 0.75 & 0.45 & 487.3 & 687.1 & 955.0 & 219.3 & 20.2 \\
\hline & Mix 21 & 0.75 & 0.50 & 475.6 & 670.6 & 932.1 & 237.8 & 20.2 \\
\hline
\end{tabular}


specimen by the transit time (T). The UPV of each specimen was calculated in kilometers per second $(\mathrm{km} / \mathrm{s})$; an average of four transit time measurements was used. Additionally, the test results of at least three specimens per mix determined the UPV of each mix at each age.

\subsection{Dynamic modulus measurement}

The dynamic modulus of each specimen was determined according to ASTM C215 (27) using the resonance test gauge after the specimens had cured in water for 3,7 , and 28 days. The dynamic modulus was determined by the impact resonance method using the longitudinal configuration, where the accelerometer and the hammer strike are directly opposite each other on parallel surfaces. Dynamic modulus of each specimen was then calculated based on the longitudinal frequency, mass, geometry, and dimension of the specimen. When defining the dynamic modulus of each specimen in $\mathrm{GPa}$, an average of three longitudinal frequency measurements was used. Additionally, the test results of at least three specimens per mix determined the dynamic modulus of each mix at each age.

\subsection{Compressive strength measurement}

The compressive strength of each of the 189 cylinders was tested according to ASTM C39 (5) after the specimens had cured in water for 3,7 , and 28 days. To determine the compressive strength of each mix at each age, an average of three cylinder compression tests per mix was used.

\section{ANALYSIS AND DISCUSSION OF RESULTS}

\subsection{Ultrasonic pulse velocity}

Some researchers have studied the development of ultrasonic pulse velocity of plain concrete over time and concluded that the rate of gain of UPV is high during early ages and then slows at later ages (28). Few investigations have been conducted on the development of the UPV of fiber-reinforced concrete over time and/or compared the development of the UPV of different fiber types over time. The development of the UPV over time of plain concrete, M1 (Mix 1 in Table 5 ), nylon fiber-reinforced concrete (NFRC), polypropylene fiber-reinforced concrete (PFRC), steel fiber-reinforced concrete, and glass fiber-reinforced concrete with different mix proportions is shown in Figure 1.

Figure 1 shows that, for these FRC mixes, the gain in UPV was rapid up to 7 days after pouring and slowed afterward, which was a result of the hydration process of concrete. The hydration process was faster at early ages because there are many un-hydrated compounds and empty spaces in the cement paste that can be filled with gel. Therefore, as time passes, the empty spaces were filled with calcium silicate hydrate, thus increasing the UPV. Materials with high density, good quality, and continuity had high velocities, while materials with low density, several cracks, and voids had slow velocities. The UPV of plain concrete (M1) was faster than that of NFRC (M2-M6) and PFRC (M7-M11) because both NFRC and PFRC have lower densities than concrete, and nylon and polypropylene fibers reduce the workability of concrete, thus forming voids. The UPV of plain concrete (M1) was closer to or lower than SFRC, such

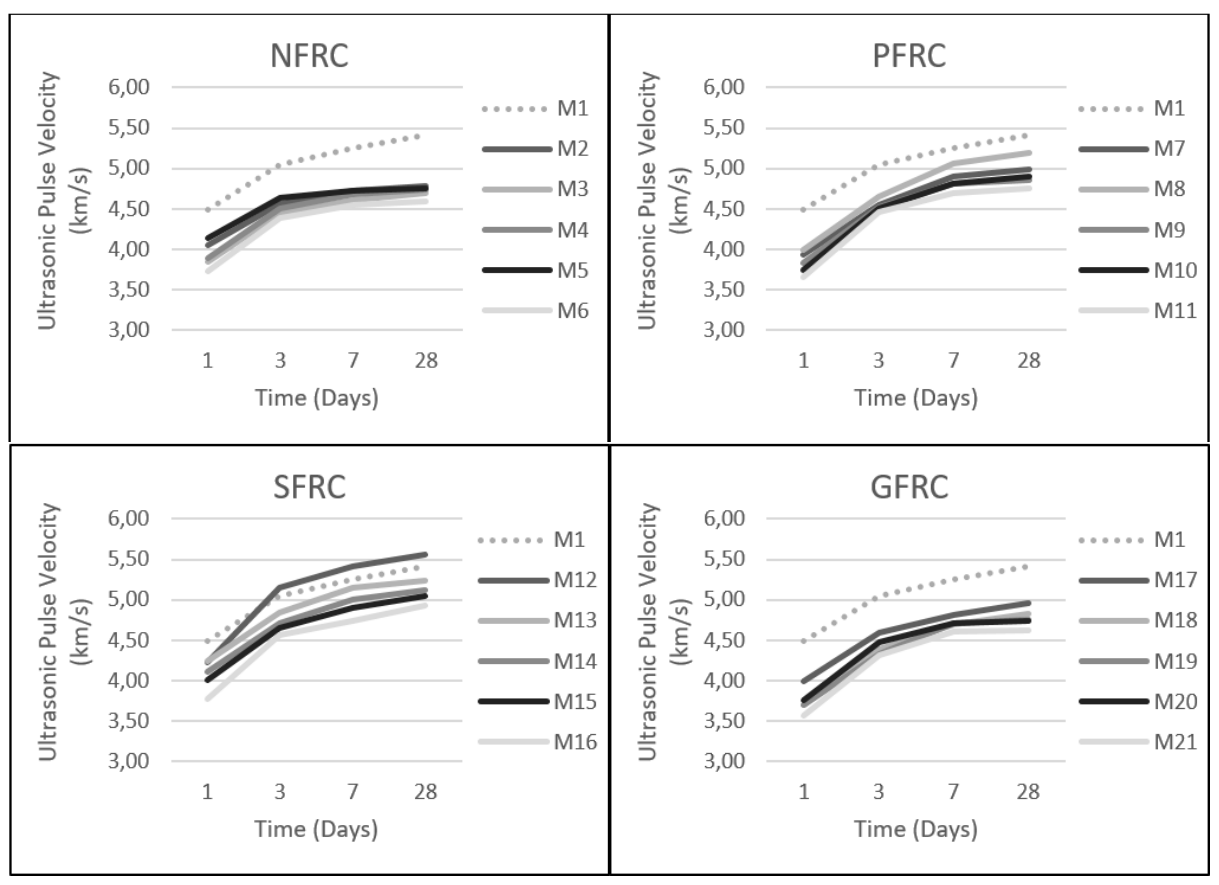

FIGURE 1. FRCs' ultrasonic pulse velocity development over time. 
as Mix 12 (M12), which had a higher UPV compared to plain concrete, because steel fibers have a higher density than concrete, and the fiber volume fraction of $0.5 \%$ vol. and water-to-cement ratio of 0.4 do not dramatically affect the workability or voids in the concrete. On the other hand, the UPV of plain concrete (M1) was higher than SFRC (M13 and M14) because fiber volume fractions higher than $0.5 \%$ reduce the workability of concrete, thus forming voids. In addition, the UPV of plain concrete (M1) was higher than SFRC (M15 and M16) because at w/c ratios higher than 0.4 , the voids in the concrete increased, and having a high $\mathrm{w} / \mathrm{c}$ ratio means less cement and aggregate content, resulting in slower velocities. The UPV of plain concrete (M1) was higher than GFRC, despite glass having a higher density than concrete, because glass fibers scatter unevenly and significantly impact the workability of concrete, thus forming voids. It can be concluded from Figure 1 that different types of structural fibers affected the UPV of FRC in different ways, depending on fiber type and volume fraction and water-to-cement ratio, and therefore a unique equation that predicts the compressive strength or dynamic modulus of all types of FRC based on UPV would not be the most accurate one. The measurements at early ages and 28 days and the observed increased rate pattern in UPV showed that a relationship exists between the early-age measurements and the mechanical properties of concrete.

\subsection{Workability}

In the current study it was observed that Polypropylene fibers increase entrapped air voids at $1.0 \%$ or higher fiber volume fractions, that results in decreasing of the concrete workability and creating difficulties when compacting the mixes, which is in agreement with the observations in similar studies (29). Nylon fibers are hydrophilic, therefore they can absorb a small amount of water during mixing (30). This characteristic can be favorable for the distribution of nylon fibers during mixing, but excess absorption at higher fiber volume fractions may adversely affect the workability of the mixtures. Similar observations were reported elsewhere (31). It was also emphasized that the structural fibers can reduce the workability of concrete mixtures and cause fiber ball production at mid-to-high fiber volume fractions, resulting in a lack of homogeneity (4). In the following sections the effect of reduction in workability on mechanical properties of specimens will be discussed.

\subsection{Compressive strength}

The gain in concrete compressive strength is rapid at an early age. This rapid early gain in strength is directly linked to the increase of the gel/space ratio of calcium silicate hydrate (3). The development of compressive strengths over time of plain concrete (M1), NFRC, PFRC, SFRC, and GFRC with different mix proportions is shown in Figure 2.

Figure 2 shows that approximately 75 percent of concrete's compressive strength was achieved in the first 7 days for all mixes, due to the hydration process, which had a faster rate at early ages. Fibers provided internal reinforcement due to the fiber-bridging effect. The fiber-bridging constitutive law describes the relationship

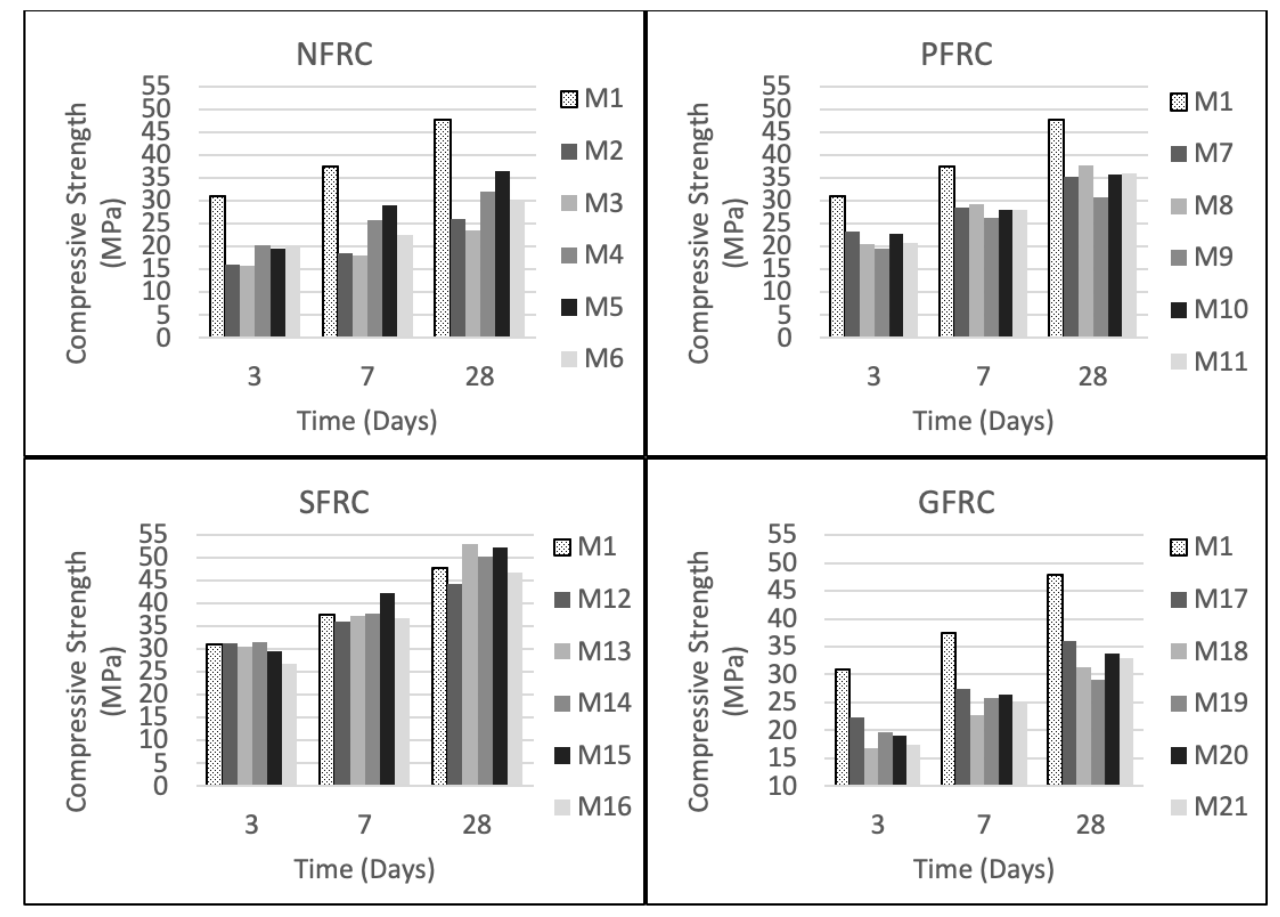

FIGURE 2. FRCs' compressive strength development over time. 
between the bridging stress transferred across a crack and the opening of this crack. However, if the workability of concrete is not high enough, the fiber-bridging effect and the performance of the FRC is reduced. Incorporating an admixture could influence the performance of FRC; for instance, the workability of FRC can be improved by using high-range water-reducing admixtures to address this problem $(32,33)$. However, that was not the focus of the current study. While the ductility and failure patterns in all FRC samples compared to plain concrete were observed to be improved during the testing process, in the fiber volume fraction range discussed in the present work, the compressive strength of plain concrete (M1) was depicted as higher than the compressive strengths of NFRC (M2-M6), PFRC (M7-M11), and GFRC (M17M21) because the properties of nylon, polypropylene, and glass fibers were not high enough to compensate for the reduction in concrete workability. The compressive strength of SFRC (M12-M16) was significantly higher than the compressive strengths of NFRC (M2-M6), PFRC (M7-M11), and GFRC (M17-M21) due to its superior fiber properties, but it was only slightly higher than the compressive strength of plain concrete (M1) due to the fiber volume fraction range considered in this study, reduced workability, and, subsequently, the lack of complete fiber-bridging effect.

\subsection{Dynamic modulus}

The gain in concrete elastic modulus is extremely rapid at an early age. This rapid early gain in strength is directly linked to the increase of the gel/space ratio of calcium silicate hydrate (3). The development of the dynamic modulus over time of plain concrete, NFRC, PFRC, SFRC, and GFRC with different mix proportions is shown in Figure 3.

Figure 3 shows that the development of the dynamic modulus of concrete was extremely rapid; approximately 80 percent of FRC's dynamic modulus was achieved in the first 3 days for all mixes. This occurred because the mixture's stiffness increases as the concrete hardens and due to the progress in the hydration process. It can also be observed that the effects of cement and aggregate content on the dynamic modulus were more impactful than the fiber volume fraction. The dynamic modulus of plain concrete was greater than that of NFRC, PFRC, and GFRC, as the elastic properties of nylon, polypropylene, and glass fibers affect the elastic properties of the composite material. The dynamic modulus of SFRC was significantly greater than that of NFRC, PFRC, and GFRC because steel fibers have superior elastic modulus, but again it can be affected due to the reduced workability.

\subsection{Prediction of early-age compressive strength of FRC}

The relationship between UPV and compressive strength of concrete at the age of 28 days has been investigated extensively in previous works, while only a few studies have discussed the relationship between UPV and compressive strength of concrete at early

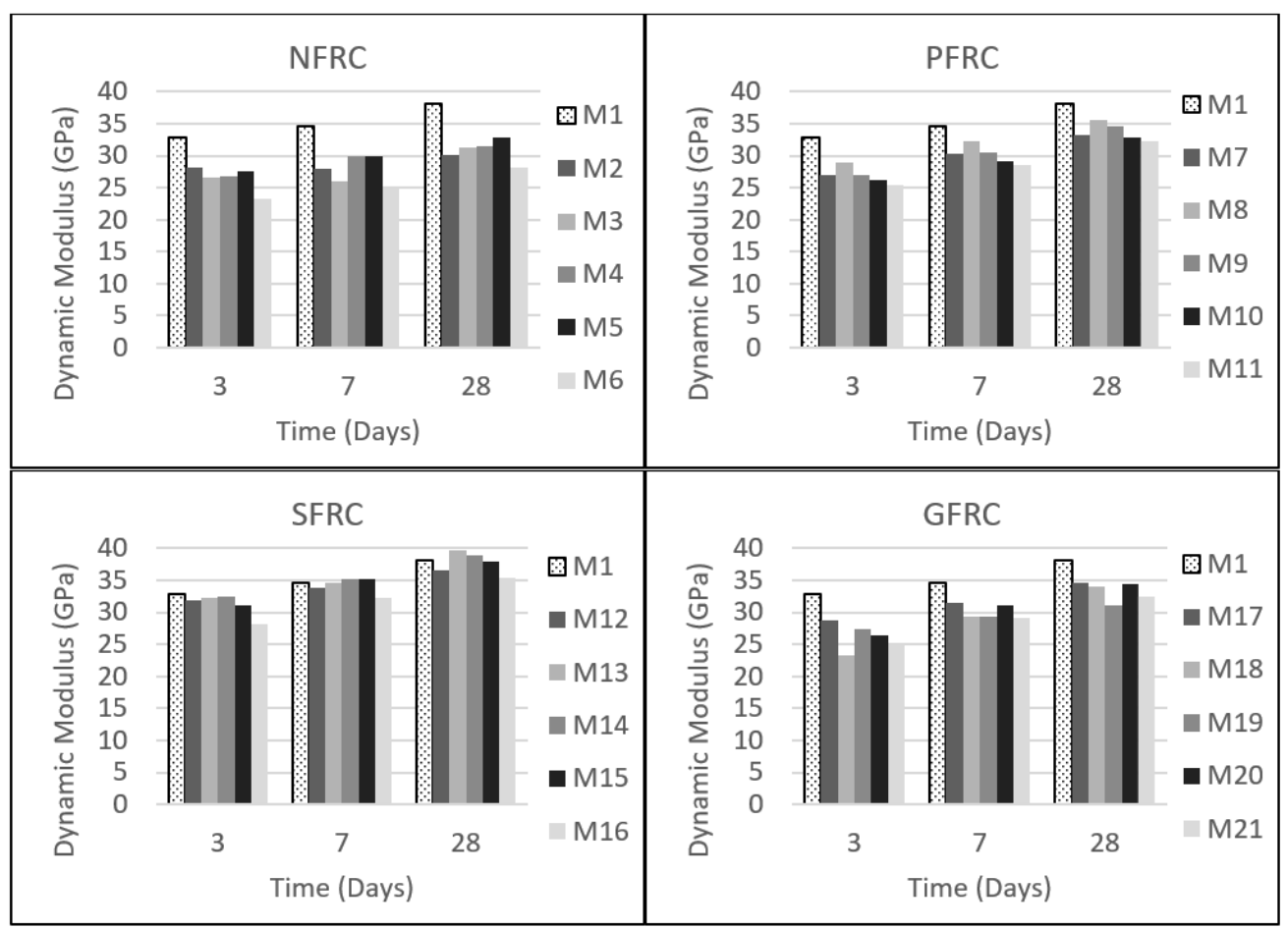

FIGURE 3. FRCs' dynamic modulus development over time. 
TABLE 6. Prediction of concrete's compressive strength based on ultrasonic pulse velocity.

\begin{tabular}{|c|c|c|}
\hline Reference & Equation & Limitation \\
\hline$(35)$ & $f_{c}=0.013 e^{1.959 V p}$ & Containing silica fume, superplasticizer, and steel fiber at 1,2 , and $3 \%$. Age -28 days \\
\hline$(35)$ & $f_{c}=0.016 e^{2.411 V_{p}}$ & $\begin{array}{l}\text { Containing silica fume, superplasticizer, and PVA fiber at } 0.25,0.5 \text {, and } 0.75 \% \text {. Age - } \\
\qquad 28 \text { days }\end{array}$ \\
\hline (36) & $f_{c}=0.15 e^{1.40 V}$ & $\begin{array}{l}\text { Containing recycled factory brick aggregate, calcium aluminate cement, silica fume, } \\
\text { superplasticizer, and polyvinyl alcohol fibers at } 0.5 \% \text { fiber volume fraction. } \\
\qquad \text { Age }-7 \text { to } 63 \text { days }\end{array}$ \\
\hline$(37)$ & $f_{c}=33.27 e^{0.582 V}$ & $\begin{array}{l}\text { High-strength concrete containing } 0,0.2,0.4 \text {, and } 0.6 \% \text { of twisted bundle non-fibrilla- } \\
\text { ted, monofilament, } \\
\text { and fibrillated polypropylene network plus silica fume. } \\
\text { Age }-7 \text { to } 63 \text { days }\end{array}$ \\
\hline (7) & $f_{c}=0.00055 e^{2.5 V}$ & $\begin{array}{c}\text { Age }-28 \text { days } \\
\mathrm{CA}=1100 \mathrm{~kg} / \mathrm{m}^{3}\end{array}$ \\
\hline$(11)$ & $f_{c}=0.0012 e^{2.27 V}$ & $\begin{array}{l}\text { Age of } 3 \mathrm{hr} \text { and over } \\
\text { Temperature } 0^{\circ} \text { to } 60^{\circ} \mathrm{C}\end{array}$ \\
\hline (13) & $f_{c}=1.19 e^{0.715 V}$ & $\begin{array}{c}\text { Age }-7 \text { to } 138 \text { days } \\
\text { Cubes }\end{array}$ \\
\hline$(38)$ & $f_{c}=2.8 e^{0.53 V}$ & Concrete slabs \\
\hline$(17)$ & $f_{c}=2.016 e^{0.61 \mathrm{~V}}$ & Concrete cubes \\
\hline$(12)$ & $f_{c}=(-109.6+33 V)$ & Concrete cylinders \\
\hline (8) & $f_{c}=9.502 \mathrm{~V}-18.89$ & $\begin{array}{l}\text { Age }-7 \text { and } 28 \text { days } \\
\text { Cubes } \\
\text { M15 grade }\end{array}$ \\
\hline (8) & $f_{c}=2.701 \mathrm{~V}-17.15$ & $\begin{array}{l}\text { Age }-7 \text { and } 28 \text { days } \\
\text { Cubes } \\
\text { M20 grade }\end{array}$ \\
\hline (8) & $f_{c}=4.104 V-19.23$ & $\begin{array}{l}\text { Age }-7 \text { and } 28 \text { days } \\
\text { Cubes } \\
\text { M35 grade }\end{array}$ \\
\hline$(14)$ & $f_{c}=8.4 * 10^{-9}\left(V * 10^{3}\right)^{2.5921}$ & Age -7 to 90 days \\
\hline
\end{tabular}

Where $f_{c}$ is compressive strength in MPa and $V$ is ultrasonic pulse velocity in $\mathrm{km} / \mathrm{s}$.

ages. It has been observed that the relationship between concrete compressive strength and ultrasonic pulse velocity is better estimated by utilizing the exponential equation forms as shown in Table 6. However, some linear relationships have also been found in the literature $(7,8,28,34)$. A new empirical equation capable of predicting the early-age compressive strength of different types of fiber-reinforced concrete at different fiber volume fractions and water-to-cement ratios is presented in this section.

The proposed Equation [1a] and Equation [1b] predict the compressive strength of 3-day and 7-day SFRC, GFRC, PFRC, and NFRC with fiber volume fractions ranging from $0.5 \%$ vol. to $1 \%$ vol. and water-to-cement ratios ranging from 0.40 to 0.50 . The development trend with hydration time is the same for both the early-age compressive strength and early-age ultrasonic pulse velocity, where compressive strength and ultrasonic pulse velocity increase exponentially over time (9). Therefore, the prediction of FRC's compressive strength at early ages based on
UPV was expressed using an exponential relationship. A coefficient of variation (COV) was used to test the accuracy of the proposed equation by comparing the measured and predicted results. The proposed equations showed good agreement with the measured values at the age of 3 days, as shown in Figure 4, and at the age of 7 days, as shown in Figure 5.

$\begin{array}{ll}\text { For G, P, and NFRC } & f_{c}=\alpha e^{0.59^{*} V} \\ \text { For SFRC } & f_{c}=\alpha e^{0.59^{* *} V}\end{array}$

Where $f_{c}$ is compressive strength $(\mathrm{MPa}), V$ is ultrasonic pulse velocity $(\mathrm{km} / \mathrm{s})$, and $\alpha$ is calculated using Equation [2] and the fiber properties in Table 2. GFRC, PFRC, and NFRC were grouped together (Equation [2a]) because they had a low density, while SFRC remained alone (Equation [2b]) because it had a higher density. 


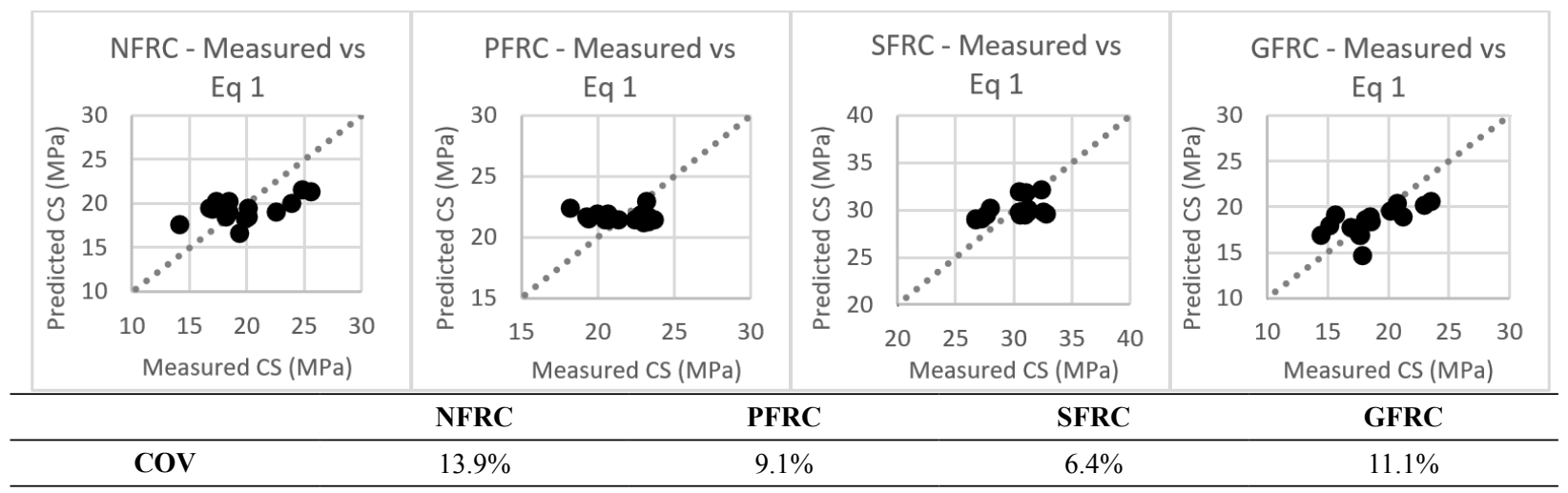

FIGURE 4. 3-day measured compressive strength vs proposed equation.

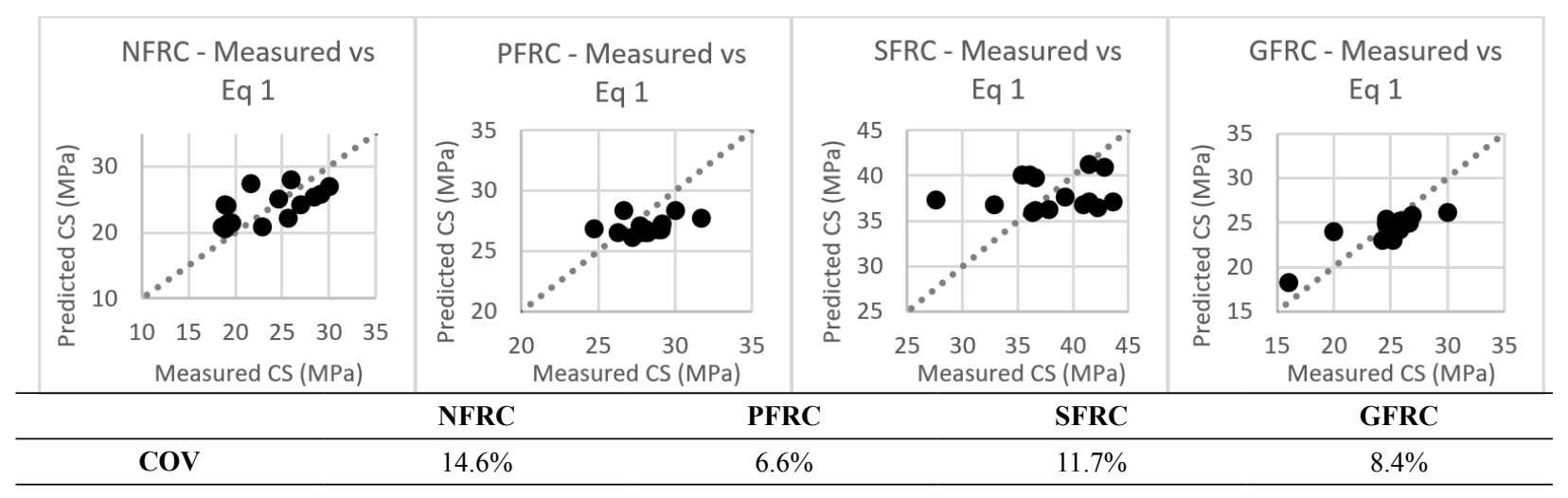

FIGURE 5. 7-day measured compressive strength vs proposed equation.

$\begin{array}{lll}\text { For G, P, and NFRC } & \alpha=0.4\left(\frac{\sigma}{V / d}\right)+t^{0.1\left(\frac{\tilde{\tau}}{p}\right)}+0.3 & {[2 \mathrm{a}]} \\ \text { For SFRC } & \alpha=1.2\left(\frac{\sigma}{V / d}\right)+t^{6.8\left(\frac{\tilde{f}}{)}\right)}+0.3 & {[2 \mathrm{~b}]}\end{array}$

Where $\sigma$ is fiber flexural strength $(\mathrm{GPa}), l$ is fiber length, $d$ is fiber diameter, $t$ is age (days), $\tau$ is fiber tensile strength $(\mathrm{MPa})$, and $\rho$ is fiber density $\left(\mathrm{kg} / \mathrm{m}^{3}\right)$.

For Figure 4 and Figure 5, the 45-degree line represents a perfect correlation between the predicted compressive strength and the measured compressive strength. Data points above this line represent unconservative deviations of the compressive strength equation 1, while data points below this line represent conservative deviations. The coefficient of variation represents the variability between the predicted and measured results. A low COV indicates good agreement between the predicted and measured values. Therefore, the proposed equations showed good agreement with the measured values.

\subsection{Prediction of the early-age dynamic modulus of FRC}

The development trend of compressive strength and dynamic modulus and ultrasonic pulse velocity with hydration time was observed to be exponential at the early ages. Therefore, the prediction of FRC's compressive strength and dynamic modulus at early ages based on ultrasonic pulse velocity is expressed using an exponential relationship which is well aligned with similar studies in the literature (9). In addition, the proposed equations can predict the compressive strength and dynamic modulus of multiple fiber reinforced concrete types, due to the incorporation of different fiber properties as variables in the equations such as: fiber flexural strength, fiber length, fiber diameter, fiber tensile strength, and fiber density. The proposed Equation [3a] and Equation [3b] predict the dynamic modulus of 3-day and 7-day SFRC, GFRC, PFRC, and NFRC with fiber volume fractions ranging from $0.5 \%$ vol. to $1 \%$ vol. and water-to-cement ratios ranging from 0.4 to 0.5 . The development trend of dynamic modulus and ultrasonic pulse velocity with hydration time is exponential at early ages (39). Therefore, the prediction of FRC's early-age dynamic modulus was calculated using an exponential equation. A COV was used to test the accuracy of the proposed equation by comparing the measured 


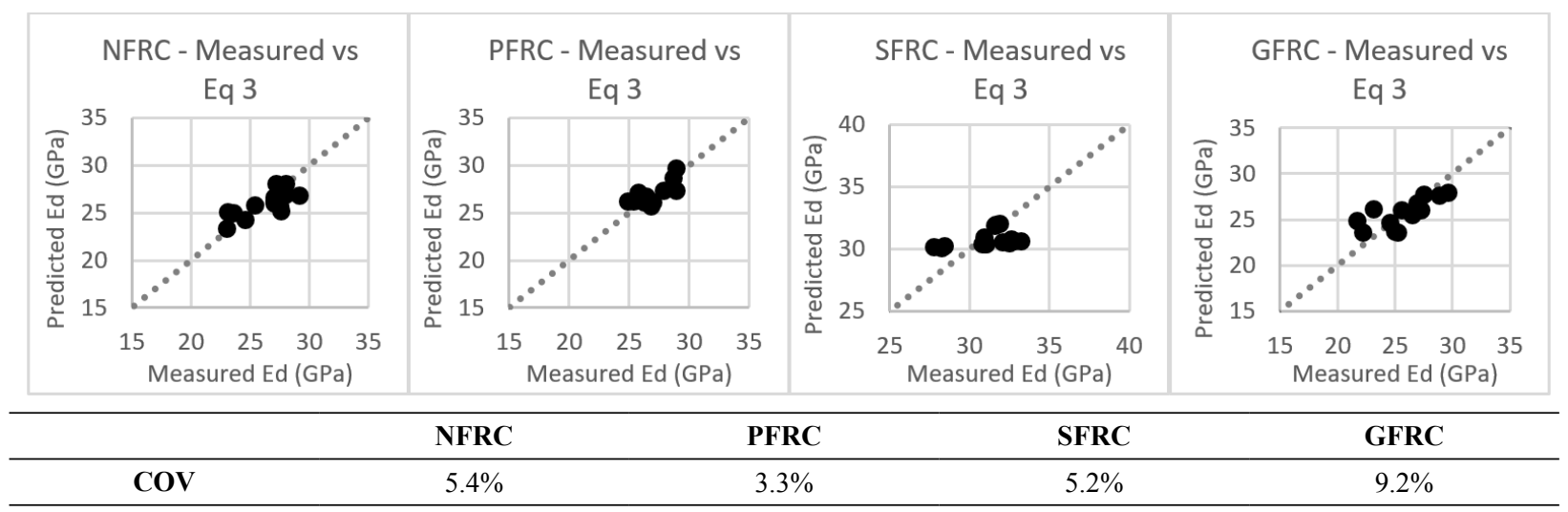

FiguRE 6. 3-day measured dynamic modulus vs proposed equation.

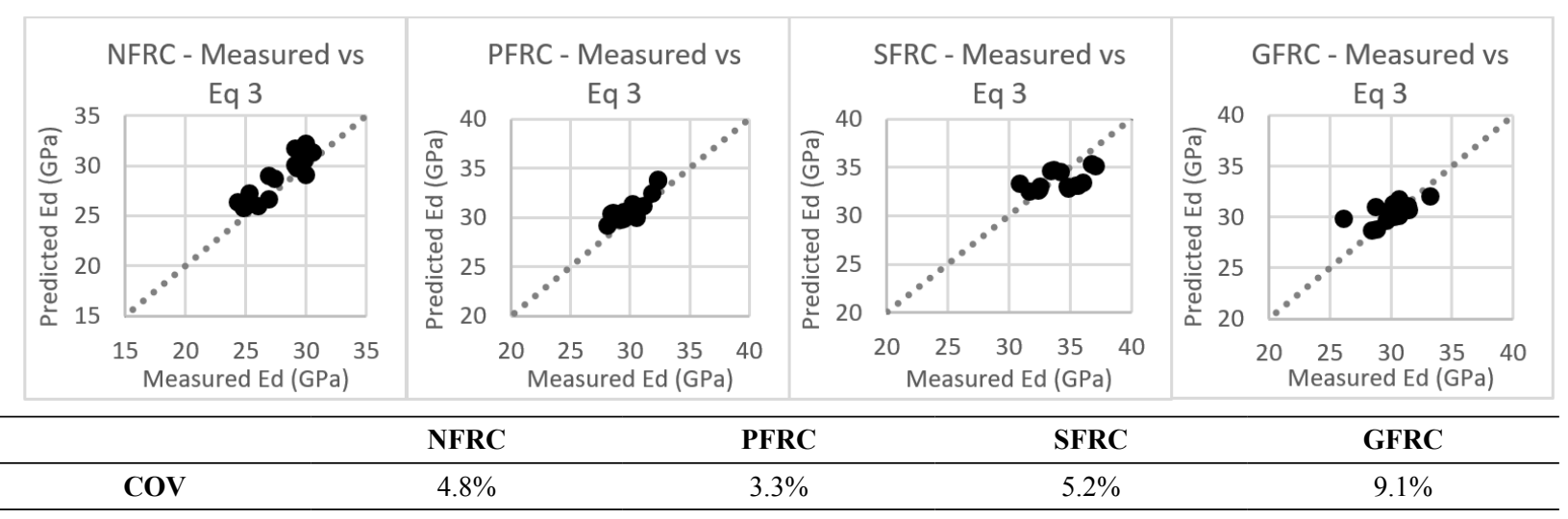

Figure 7. 7-day measured dynamic modulus vs proposed equation.

and predicted results. The proposed equations showed good agreement with the measured values at the age of 3 days, as shown in Figure 6, and at the age of 7 days, as shown in Figure 7.

$$
\begin{array}{ll}
\text { For G, P, and NFRC } & E_{d}=\alpha e^{0.46^{*} V} \\
\text { For SFRC } & E_{d}=\alpha e^{0.09^{*} V}
\end{array}
$$

Where $E_{d}$ is the dynamic modulus (GPa), $V$ is the ultrasonic pulse velocity $(\mathrm{km} / \mathrm{s})$, and $\alpha$ is calculated using Equation [4] and the fiber properties listed in Table 2. GFRC, PFRC, and NFRC were grouped together because they each had a low density, while SFRC remained alone because it had a high density.

$$
\begin{array}{ll}
\text { For G, P, and NFRC } & \alpha=0.3\left(\frac{\sigma}{l^{\prime} d}\right)+t^{0.2\left(\frac{(1)}{p}\right)}+2 \\
\text { For SFRC } & \alpha=1.7\left(\frac{\sigma}{l^{\prime} d}\right)+t^{4.6\left(\frac{\left(\frac{(}{p}\right)}{p}+2\right.}
\end{array}
$$

Where $\sigma$ is fiber flexural strength $(\mathrm{GPa}), l$ is fiber length, $d$ is fiber diameter, $t$ is age ( 3 or 7 days), $\tau$ is fiber tensile strength (MPa), and $\rho$ is fiber density $\left(\mathrm{kg} / \mathrm{m}^{3}\right)$.

Figure 6 and Figure 7, the 45-degree line represents a perfect correlation between the predicted dynamic modulus and measured dynamic modulus. Data points above this line represent unconservative deviations of the dynamic modulus Equation [3], while data points below this line represent conservative deviations. The coefficient of variation represents the variability between the predicted and measured results. A low COV indicates good agreement between the predicted and measured values; therefore, the proposed equations showed good agreement with the measured values.

\section{CONCLUSIONS}

This paper investigates the correlation between the early-age ultrasonic pulse velocity and the early-age compressive strength and dynamic modulus of nylon, polypropylene, steel, and glass fiber-reinforced concrete. The study was needed because the preliminary study conducted prior to this research revealed that the existing equations did not provide 
a good prediction of fiber-reinforced concrete's early-age compressive strength and/or dynamic modulus based on UPV. The mixture parameters investigated included fiber volume fractions of $0.5 \%$ vol., $0.75 \%$ vol., and $1.00 \%$ vol., and water-to-cement ratios of $0.40,0.45$, and 0.50 . The ultrasonic pulse velocity, compressive strength, and dynamic modulus were measured for the specimens using an ultrasonic concrete tester, compression test machine, and resonance test gauge, respectively. Two sets of equations were proposed to predict the early-age compressive strength and dynamic modulus of FRC based on ultrasonic pulse velocity. The first set of equations predicted the 3-day and 7-day compressive strength of nylon, polypropylene, steel, and glass fiber-reinforced concrete. The second set of equations predicted the 3-day and 7-day dynamic modulus of nylon, polypropylene, steel, and glass fiber-reinforced concrete. The proposed equations can predict the early-age compressive strength and dynamic modulus of multiple fiber-reinforced concrete types, due to the incorporation of different fiber properties as variables in the equations. No other equations have been found in the literature capable of accurately predicting the early-age compressive strength and dynamic modulus of multiple types of fiber-reinforced concrete with different mixture parameters.

The accuracy of these new equations was tested by measuring the coefficient of variation between the measured values and the predicted values from the proposed equations. The coefficients of variation between the measured and predicted compressive strengths showed reasonable agreement with the measured values, and ranged from 6.4 to 14.6 percent. The coefficients of variation between the measured and predicted dynamic moduli also showed reasonable agreement with the measured dynamic moduli, and ranged from 3.3 to 9.2 percent. Based on these results, it appears that the proposed Equation [1a] and Equation [1b] can accurately predict the 3-day and 7-day compressive strength of nylon, polypropylene, steel, and glass fiber-reinforced concrete. Similarly, based on the results, it appears that the proposed Equation [3a] and Equation [3b] can accurately predict the 3-day and 7-day dynamic modulus of nylon, polypropylene, steel, and glass fiber-reinforced concrete.

\section{AUTHORS CONTRIBUTIONS}

Conceptualization: D. Castillo, S. Hedjazi. Data curation: D. Castillo. Formal analysis: D. Castillo, S. Hedjazi. Investigation: D. Castillo, S. Hedjazi. Methodology: S. Hedjazi. Project administration: S. Hedjazi. Resources: S. Hedjazi. Supervision: S. Hedjazi. Validation: D. Castillo, S. Hedjazi. Visualization: D. Castillo. Roles/Writing, original draft: D. Castillo. Writing, review \& editing: S. Hedjazi.

\section{REFERENCES}

1. Nehdi, M.L.; Soliman, A.M. (2011) Early-age properties of concrete: Overview of fundamental concepts and state-ofthe art research. Constr. Mater. 164 [2], 57-77. https://doi. org/10.1680/coma.900040.

2. Pane, I.; Hansen, W. (2002) Early-age creep and stress relaxation of concrete containing blended cements. Mater. Struc. 35, 92. https://doi.org/10.1007/BF02482107.

3. Neville, A.M. (2004) Properties of Concrete, 4th edition. Wiley Harlow, New York, USA, (2004).

4. American Society for Testing Materials (2015) Standard specification for fiber-reinforced concrete. ASTM C1116. 100 Barr Harbor Drive, PO Box C700, West Conshohocken, PA 19428-2959, USA, (2015). https://doi.org/10.1520/C1116_ C1116M-10AR15.

5. American Society for Testing Materials (2012) Standard test method for compressive strength of cylindrical concrete specimens. ASTM C39. 100 Barr Harbor Drive, PO Box C700, West Conshohocken, PA 19428-2959, USA, (2012). https:// doi.org/10.1520/C0039_C0039M-12.

6. American Society for Testing Materials (2010) Standard test method for static modulus of elasticity and Poisson's ratio of concrete in compression. ASTM C469. 100 Barr Harbor Drive, PO Box C700, West Conshohocken, PA 19428-2959, USA, (2010). https://doi.org/10.1520/C0469 C0469M-10.

7. Lin, Y.; Kuo, S-F.; Hsiao, C.; Lai, C-P. (2007) Investigation of pulse velocity-strength relationship of hardened concrete. ACI Mater. J. 104 [4], 344-350. https://doi. org/10.14359/18823.

8. Mahure, N.; Vijh, G.; Sharma, P.; Sivakumar, N.; Ratnam, M. (2011) Correlation between pulse velocity and compressive strength of concrete. Inter. J. Ear. Sci. Eng. 4 [6], 871-874.

9. Khademi, F.; Akbari, M.; Jamal, S.M. (2016) Prediction of concrete compressive strength using ultrasonic pulse velocity test and artificial neural network modeling. Roma. J. Mater. 46 [3], 343-350.

10. Ding, Y.; Kusterle, W. (2000) Compressive stress-strain relationship of steel fibre-reinforced concrete at early age. Cem. Concr. Res. 30 [10], 1573-1579. https://doi.org/10.1016/ s0008-8846(00)00348-3.

11. Elvery, R.; Ibrahim, L. (1976) Ultrasonic assessment of concrete strength at early ages. Mag. Concr. Res. 28 [97], 181190. https://doi.org/10.1680/macr.1976.28.97.181.

12. Naik, T.; Malhotra, V.; Popovics, J. (2003) The ultrasonic pulse velocity method. In: Handbook on nondestructive testing of concrete, Second Edition, 8-1 to 8-19, CRC Press, (2003).

13. Nash't, I.; A'bour, S.; Sadoon, A. (2005) Finding an unified relationship between crushing strength of concrete and non-destructive tests. Mid. East Nond. Test. Conf. Exhi. 2730. Nov., Bahrain, Manama, (2005).

14. Kheder, G. (1999) A two stage procedure for assessment of in situ concrete strength using combined non-destructive testing. Mater. Struct. 32, 410. https://doi.org/10.1007/ BF02482712.

15. Gebretsadik, B. (2013) Ultrasonic pulse velocity investigation of steel fiber reinforced self-compacted concrete. UNLV Theses, Dissertations, Professional Papers, and Capstones, 1828, University of Nevada, Las Vegas, USA. https://doi. org/10.34917/4478246.

16. Nitin; Verma, S.K. (2016) Effect on mechanical properties of concrete using nylon fibers. Inter. Res. J. Eng. Tech. 3 [7], 1751-1755.

17. Raouf, Z.; Ali, Z. (1983) Assessment of concrete characteristics at an early age by ultrasonic pulse velocity. J. Build. Res. 2 [1], 31-44.

18. Suksawang, N.; Wtaife, S.; Alsabbagh, A. (2018) Evaluation of elastic modulus of fiber-reinforced concrete. ACI Mater. J. 115 [2], 239-249. https://doi.org/10.14359/51701920 .

19. Nycon. (2020) Nylon Fibers. Fairless Hills, PA, (2021). https://nycon.com/collections/nylon-fibers.

20. Bobde, S.P.; Gandhe, G.R.; Tupe, D.H. (2018) Performance of glass fiber reinforced concrete. Inter. J. Advan. Res. Ideas Inno. Tech. 4 [3], 984-988.

21. Zheng, Y.; Wu, X.; He, G.; Shang, Q.; Xu, J.; Sun, Y. (2018) Mechanical properties of steel fiber-reinforced concrete by 
vibratory mixing technology. Adv. Civil Eng. 2018, 1-11. https://doi.org/10.1155/2018/9025715.

22. Ramli, M.; Hoe, K.W. (2010) Influences of short discrete fibers in high strength concrete with very coarse sand. Amer. J. Appl. Scie. 7 [12], 1572-1578. https://doi.org/10.3844/ ajassp.2010.1572.1578

23. Pawade, P.; Nagarnaik, P.; Pande, A. (2011) Performance of steel fiber on standard strength concrete in compression. Inter. J. Civil Struc. Eng. 2 [2], 483-492.

24. Mohod, M.V. (2015) Performance of polypropylene fiber reinforced concrete. IOSR J. Mech. Civil Eng. 12 [1], 28-36.

25. American Society for Testing Materials. (2019) Standard practice for making and curing concrete test specimens in the laboratory. ASTM C192. 100 Barr Harbor Drive, PO Box C700, West Conshohocken, PA 19428-2959, USA, (2019). https://doi.org/10.1520/C0192 C0192M-19.

26. American Society for Testing Materials. (2016) Standard test method for pulse velocity through concrete. ASTM C597. 100 Barr Harbor Drive, PO Box C700, West Conshohocken, PA 19428-2959, USA, (2016). https://doi.org/10.1520/ C0597-16.

27. American Society for Testing Materials. (2019) Standard test method for fundamental transverse, longitudinal, and torsional resonant frequencies of concrete specimens. ASTM C215. 100 Barr Harbor Drive, PO Box C700, West Conshohocken, PA 19428-2959, USA, (2019). https://doi.org/10.1520/C0215-19.

28. Yoon, H.; Kim, Y.J.; Kim, H.S.; Kang, J.W.; Koh, H-M. (2017) Evaluation of early-age concrete compressive strength with ultrasonic sensors. Sensors. 17 [8], 1817. https://doi. org/10.3390/s17081817.

29. Madhavi, T.C.; Raju, L.S.; Mathur, D. (2014). Polypropylene fiber reinforced concrete - a review. Inter. J. Emer. Tech. Advan. Engin. 4 [4], 114-119.

30. Zollo, R.F. (1997) Fiber-reinforced concrete: an overview after 30 years of development. Cem. Concr. Comp. 19 [2], 107-122. https://doi.org/10.1016/S0958-9465(96)00046-7.
31. Song, P.S.; Hwang, S.; Sheu, B.C. (2015). Strength properties of nylon and polypropylene fiber reinforced concretes. Cem. Concr. Res. 35 [8], 1546-1550. https://doi.org/10.1016/j.cemconres.2004.06.033.

32. Thirumurugan, S.; Sivakumar, A. (2013) Compressive strength index of crimped polypropylene fibers in high strength cementitious matrix. World Appli. Scien. J. 24 [6], 698-702.

33. Yang, E-H.; Wang, S.; Yang, Y.; Li, V.C. (2008) Fiber-bridging constitutive law of engineered cementitious composites. J. Advan. Concr. Tech. 6 [1], 181-193. https://doi. org/10.3151/jact.6.181.

34. Popovics, S.; Rose, J.; Popovics, J. (1990) The behaviour of ultrasonic pulses in concrete. Cem. Concr. Res. 20 [2], 259270. https://doi.org/10.1016/0008-8846(90)90079-D

35. Nematzadeh, M.; Poorhosein, R. (2017) Estimating properties of reactive powder concrete containing hybrid fibers using UPV. Comp. Concr. 20 [4], 491-502. https://doi. org/10.12989/cac.2017.20.4.491.

36. Nematzadeh, M.; Dashti, J.; Ganjavi, B. (2018) Optimizing compressive behavior of concrete containing fine recycled refractory brick aggregate together with calcium aluminate cement and polyvinyl alcohol fibers exposed to acidic environment. Constr. Build. Mater. 164, 837-849. https://doi. org/10.1016/j.conbuildmat.2017.12.230.

37. Nematzadeh, M.; Fallah-Valukolaee, F. (2017) Erosion resistance of high-strength concrete containing forta-ferro fibers against sulfuric acid attack with an optimum design. Constr. Build. Mater. 154, 675-686. https://doi.org/10.1016/j. conbuildmat.2017.07.180.

38. Jones, R. (1962) Non-destructive Testing of Concrete. Cambridge University Press, London, (1962).

39. Haque, M.A.; Rasel-Ul-Alam, Md. (2018) Non-linear models for the prediction of specified design strengths of concretes development profile. HBRC J. 14 [2], 123-136. https://doi. org/10.1016/j.hbrcj.2016.04.004. 